\title{
Simulation of Potato Late Blight in the Andes. II: Validation of the LATEBLIGHT Model
}

\author{
Jorge L. Andrade-Piedra, Robert J. Hijmans, Henry S. Juárez, \\ Gregory A. Forbes, Dani Shtienberg, and William E. Fry
}

First author: Department of Plant Pathology, 213 Bradfield Hall, Cornell University, Ithaca, NY 14853; second, third, and fourth authors: International Potato Center (CIP), P.O. Box 1558, Lima 12, Peru; fifth author: Department of Plant Pathology, ARO, The Volcani Center, Bet Dagan 50250, Israel; and sixth author: Department of Plant Pathology, 334 Plant Sciences Building, Cornell University, Ithaca, NY 14853.

Current address of J. L. Andrade-Piedra: International Potato Center (CIP), P.O. Box 1721 1977, Quito, Ecuador.

Current address of R. J. Hijmans: Museum of Vertebrate Zoology, University of California, 3101 Valley Life Sciences Building, Berkeley 94720.

Accepted for publication 17 June 2005.

\begin{abstract}
Andrade-Piedra, J. L., Hijmans, R. J., Juárez, H. S., Forbes, G. A., Shtienberg, D., and Fry, W. E. 2005. Simulation of potato late blight in the Andes. II: Validation of the LATEBLIGHT model. Phytopathology 95:1200-1208.

LATEBLIGHT, a mathematical model that simulates the effect of weather, host growth and resistance, and fungicide use on asexual development and growth of Phytophthora infestans on potato foliage, was validated for the Andes of Peru. Validation was needed due to recent modifications made to the model, and because the model had not been formally tested outside of New York State. Prior to validation, procedures to estimate the starting time of the epidemic, the amount of initial inocu-

epidemics. These data had not been used previously for estimating model parameters. Observed and simulated epidemics were compared graphically using disease progress curves and numerically using the area under the disease progress curve in a confidence interval test, an equivalence test, and an envelope of acceptance test. The level of agreement between observed and simulated epidemics was high, and the model was found to be valid according to subjective and objective performance criteria. The approach of measuring fitness components of potato cultivars infected with isolates of a certain clonal lineage of $P$. infestans under controlled conditions and then using the experimental results as parameters of LATEBLIGHT proved to be effective. Fungicide treatments were not considered in this study.
\end{abstract} lum, and leaf wetness duration were developed. Observed data for validation were from field trials with three potato cultivars in the Peruvian locations of Comas and Huancayo in the department of Junín, and Oxapampa in the department of Pasco in 1999 and 2000 for a total of 12
Additional keywords: data validation, operational validation, tropical highlands.
LATEBLIGHT is a mathematical model that simulates the effect of weather, host growth and resistance, and fungicide use on asexual development and growth of Phytophthora infestans on potato foliage. Andrade-Piedra et al. (4) modified this model so that it can be used in the Andes and, eventually, worldwide. This was needed because the previous version of the model (referred to as LB1990 [4]) is invalid outside the conditions for which it was originally calibrated due to the following limitations: (i) some of the original parameters and equations represent a $P$. infestans population that has been displaced by new, more aggressive populations; (ii) a key fitness component is assumed to be constant at all temperatures, while experimental data shows the opposite; and (iii) several parameters obtained by calibration are out of range of experimentally observed values and, therefore, are biologically meaningless (4). The modifications, therefore, included the incorporation of improved equations for the effect of temperature on lesion growth rate (LGR) (Table 1 provides a list of acronyms and abbreviations) and sporulation rate (SR) in isolates from a clonal lineage that belongs to the new populations of P. infestans; the incorporation of temperature-dependent latent period (LP); and the use of experimentally measured parameters of LGR, SR, and LP

Corresponding author: J. L. Andrade-Piedra; E-mail address: j.andrade @ cgiar.org

DOI: 10.1094/PHYTO-95-1200

(c) 2005 The American Phytopathological Society of specific potato cultivars and pathogen lineages (4). The resulting version of the model was referred to as LB2004 (4).

Because of these changes, and because the model was previously tested formally only near Ithaca, NY $(8,11)$, further validation of the model was needed. In the present study, we validate LB2004 using data obtained from experiments located in Peru. We do not validate the fungicide submodel here, and only report on epidemics in which no fungicides were used. The objective of validation is to test if the model is reasonably accurate within its domain of applicability and consistent with its intended application $(34,36)$. The domain of applicability, i.e., the "prescribed conditions for which the computerized model has been tested, compared against reality to the extent possible, and judged suitable for use" (36), are the Peruvian Andes, as we use data from that region only. The intended application of the model is for research and education. For example, we intend to use model results to demonstrate epidemiological principles of disease management to diverse audiences and to improve and focus field experiments by developing and testing hypotheses about the integration of partially resistant cultivars and, eventually, fungicides in diverse environmental conditions.

Before validation could take place, there were three variables that needed to be estimated. The first two are the starting time of the epidemic and the amount of initial inoculum, which initiate the simulation of disease. In the epidemics used to validate the two previous versions of the model, the plants were artificially 
inoculated to ensure the presence of the disease $(8,11)$. Thus, initial inoculum, expressed either as lesions per plant or sporangia per unit area, at a certain point in time, was known. In contrast, in our field experiments the plants were infected by natural inoculum because air-dispersed sporangia were present at emergence, which is true in many parts of the Andes $(1,10,28)$. With natural inoculum, the starting time of the epidemic and the amount of initial inoculum needed to be estimated.

The third variable to be estimated is leaf wetness duration (LWD). In previous versions of LATEBLIGHT, LWD was estimated with a simple empirical model that assumes occurrence of leaf wetness from dew whenever relative humidity $(\mathrm{RH})$ is above a commonly used threshold $(90 \%)$ as measured by a sensor located within the potato canopy $(7,8,11,16)$. However, the RH sensor is located at screen height (approximately $1.5 \mathrm{~m}$ ) in most field experiments and, since RH is usually lower above the canopy than within, LWD would be underestimated. Moreover, to make the model more widely applicable, data measured in standard weather stations should be suitable for model input, and RH is also measured at screen height at those stations. Therefore, it was necessary to develop a procedure to compare RH measurements taken above and within the canopy in order to estimate LWD with RH measured above the canopy.

In this study, we used field data from Peru to assess the reliability of LB2004 for research and education purposes. The first step was to analyze the field data to determine their variance and to make certain that there were no obvious errors (data validation [35]). Then, we developed procedures to estimate the starting time of the epidemic and the amount of initial inoculum, and to compare RH measured above and within the canopy in order to estimate LWD. Finally, we compared epidemics simulated by LB2004 with those observed in the real system (operational validation [35]) using graphical and statistical tests. The level of agreement between model output and reality was assessed by comparison with subjective and objective performance criteria (33). The output of LB2004 was not compared with that of LB1990 because of the invalidity of LB1990 outside the conditions for which it was originally calibrated.

\section{MATERIALS AND METHODS}

Field experiments. Trials were conducted in three locations in Peru: Comas and Huancayo in the department of Junín, and Oxapampa in the department of Pasco (Table 2). Three potato cultivars, for which the parameters needed for LB2004 were previously obtained (4), 'Tomasa Tito Condemayta' (hereafter referred to as 'Tomasa'), 'Yungay', and 'Amarilis-INIA' (hereafter referred to as 'Amarilis'), were planted in four experiments for a total of 12 epidemics. Cv. Tomasa has been reported as highly susceptible to $P$. infestans, cv. Yungay as moderately resistant, and cv. Amarilis as resistant (13). Data from the field experiments had not been used previously for estimating model parameters.

Potato plants were grown in 4.0- to 4.2-m-long plots, each with four rows that were $1.0 \mathrm{~m}$ apart. Plots (experimental units) were randomly allocated to each cultivar in a randomized complete block design and separated from each other by a strip of $4.0 \mathrm{~m}$ of

TABLE 1. Acronyms and abbreviations used in this study

\begin{tabular}{|c|c|c|}
\hline Acronym or abbreviation & Definition & Unit \\
\hline A1L & Area of one lesion & $\mathrm{m}^{2}$ lesion $^{-1}$ \\
\hline $\mathrm{AUDPC}_{\mathrm{obs}}$ & Observed area under the disease progress curve & Percent-days \\
\hline$\overline{\mathrm{AUDPC}}_{\mathrm{obs}}$ & Mean $\mathrm{AUDPC}_{\mathrm{obs}}$ & Percent-days \\
\hline$\overline{\mathrm{AUDPC}}_{\mathrm{sim}}$ & Mean $\mathrm{AUDPC}_{\mathrm{sim}}$ & Percent-days \\
\hline CIT & Confidence interval test & - \\
\hline DAE & Days after emergence & - \\
\hline EAT & Envelope of acceptance test & - \\
\hline EC-1 & Clonal lineage of Phytophthora infestans widely distributed in Peru (30) & - \\
\hline $\mathrm{GC}$ & Ground covered by potato foliage & Proportion \\
\hline $\mathrm{H}$ & $\begin{array}{l}\text { Daily period when relative humidity was above } 85 \% \text { (sensor located above the potato } \\
\text { canopy) or } 90 \% \text { (sensor located within the potato canopy) }\end{array}$ & 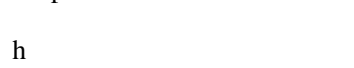 \\
\hline$\overline{\mathrm{H}}$ & Mean $\mathrm{H}$ during the experiments & $\mathrm{h}$ \\
\hline LA & Lesion area on $t_{1}$ & $\mathrm{~m}^{2} \mathrm{~m}^{-2}$ of ground \\
\hline LAI & Leaf area index & $\mathrm{m}^{2} \mathrm{~m}^{-2}$ of ground \\
\hline LB2004 & Most recent version of LATEBLIGHT (4) & - \\
\hline LGR & Lesion growth rate & $m$ day $^{-1}$ \\
\hline LP & Latent period & Days \\
\hline LWD & Leaf wetness duration & $\mathrm{h}$ \\
\hline RAUDPC $_{\mathrm{obs}}$ & Observed relative area under the disease progress curve & $\%$ \\
\hline$\overline{\text { RAUDPC }}_{\mathrm{obs}}$ & Mean RAUDPC ${ }_{\text {obs }}$ & $\%$ \\
\hline $\mathrm{RH}$ & Relative humidity & $\%$ \\
\hline $\mathrm{S}$ & Severity of late blight & $\%$ \\
\hline SD & Standard deviation of the mean & - \\
\hline SE & Standard error of the mean & - \\
\hline SR & Sporulation rate & Sporangia $\mathrm{m}^{-2}$ day $^{-1}$ \\
\hline
\end{tabular}


barley. The number of replications was four. Whole tubers of approximately $60 \mathrm{~g}$ each were planted at 0.26 to $0.30 \mathrm{~m}$ spacing in the row, resulting in a density of between 3.3 plants $\mathrm{m}^{-2}$ (Huancayo and Oxapampa, 2000) and 3.8 plants $\mathrm{m}^{-2}$ (Comas and Oxapampa, 1999). Planting dates were 12 January 1999 (Comas), 22 January 1999 (Oxapampa, 1999), 16 December 1999 (Huancayo), and 27 November 1999 (Oxapampa, 2000). Ammonium nitrate, diammonium phosphate, and potassium chloride were applied at planting at the rate of $80-140-120 \mathrm{~N}-\mathrm{P}-\mathrm{K} \mathrm{kg} \mathrm{ha}{ }^{-1}$. The plants were hilled and fertilized again with ammonium nitrate $\left(80 \mathrm{~kg} \mathrm{~N} \mathrm{ha}^{-1}\right)$ 35 days after planting. The insecticide carbofuran (Furadan) at the rate of $1 \mathrm{~kg} \mathrm{ha}^{-1}$ and the herbicide metribuzin (Sencor) at the rate of $0.19 \mathrm{~kg} \mathrm{ha}^{-1}$ were also applied at planting. There were no applications of fungicides, except on plots that were used to estimate the growing period of a healthy crop (data not shown).

Late blight epidemics started from natural inoculum. The genotype of $P$. infestans was not identified, although the experiments were located in areas where potatoes are predominantly infected with isolates of the EC-1 clonal lineage (30). Severity of late blight, expressed as the percentage of foliage infected on a plot basis, was estimated visually every 4 to 6 days starting 5 to 12 days after emergence (DAE) following the method described by Fry (14). Epidemics were evaluated until healthy plants in plots with chemical control were mature (98 to $139 \mathrm{DAE}$ ).

Temperature and RH were measured using sensors sheltered from direct solar radiation located within a potato canopy at 0.15 to $0.50 \mathrm{~m}$ (Oxapampa, 1999) or above the canopy at 1.50 to $1.70 \mathrm{~m}$ (Comas, Huancayo, and Oxapampa, 2000). The following automated data loggers were used: Hobo (Model Pro RH/Temp, Onset Computer Corporation, Pocasset, MA) and Watchdog (Model 450, Spectrum Technologies, Plainfield, IL). The sensors were sampled every 15 to $60 \mathrm{~min}$, and the following daily variables were calculated: mean air temperature ( $\mathrm{T}$, degrees Celsius), period when $\mathrm{RH}>x$ (H, hours), and mean air temperature when $\mathrm{RH}>x$ (TH, degrees Celsius), where $x=85$ or $90 \%$ depending whether the temperature/RH sensor was located above or within the potato canopy, respectively (described below).

Analysis of field data. The observed relative area under the disease progress curve (RAUDPC $\mathrm{obs}_{\mathrm{ob}}$, percent) was used to analyze the data of each epidemic in the field (combination cultivarlocation-year). Observed AUDPC (AUDPC ${ }_{\text {obs }}$, percent-days) was first calculated (9) for each plot and then divided by the disease duration (15), which was estimated as the period (days) between the appearance of the first lesions and the end of the growing period of a healthy crop. Then, the $95 \%$ confidence interval of the mean of RAUDPC ${ }_{\text {obs }}\left(\overline{\text { RAUDPC }}_{\text {obs }}\right.$ ) was calculated based on a $t$ distribution for each epidemic (37). Normal probability plots and scatter plots of standardized residuals on the estimated mean were used to check normality of RAUDPC ${ }_{\mathrm{obs}}$ and presence of outliers (23). Within an experiment, cultivars with non-overlapping confidence intervals of $\overline{\text { RAUDPC}}_{\mathrm{obs}}$ were statistically different among each other at $\alpha=0.05$.

Estimation of initial inoculum. When epidemics are initiated from natural aerial inoculum in the Andes, infection can occur at any time after emergence of the crop. In order to estimate the day of initiation (DOI, DAE) of the simulated epidemic, it was assumed that (i) late blight was first observable between the last evaluation on which no lesions were observed ( $t_{0}$, DAE) and the first evaluation they were observed $\left(t_{1}, \mathrm{DAE}\right)$; and (ii) late blight was not readily observed during the LP of the first lesions. Therefore, DOI was set using equation 1 :

$$
\mathrm{DOI}=\left[\left(t_{0}+t_{1}\right) / 2\right]-\mathrm{LP}
$$

where LP = temperature-dependent LP of the specific cultivarlineage interaction (days) generated by LB2004.

The initial number of lesions for the simulated epidemic (IL, lesions per square meter of ground) on DOI was estimated as the quotient between lesion area on $t_{1}$ (LA, square meter per square meter of ground) and the area of one lesion (A1L, square meter per lesion). LA was calculated with equation 2 :

$$
\mathrm{LA}=\mathrm{LAI}_{t_{1}} \times \mathrm{S}_{t_{1}} / 100
$$

where LAI = leaf area index (square meter per square meter of ground) generated by the model and $\mathrm{S}=$ severity (\%). The A1L was calculated with equation 3 :

$$
\mathrm{A} 1 \mathrm{~L}=\pi \times\left(0.001+\sum_{i=y}^{n=t_{1}} \mathrm{LGR}_{i}\right)^{2}
$$

where LGR = temperature-dependent LGR of the specific cultivar-lineage interaction (meters per day) at the $i$ th DAE, $y=$ $\left\{\left[\left(t_{0}+t_{1}\right) / 2\right]+1\right\} \mathrm{DAE}$, and $0.001=$ radius of the lesion when it becomes visible (meters) (7). In order to make comparisons among experiments, IL was adjusted for the proportion of ground covered by potato foliage $\left(\mathrm{IL}_{\mathrm{GC}}\right.$, lesions per square meter of ground covered by foliage) according to equation 4 :

$$
\mathrm{IL}_{\mathrm{GC}}=\mathrm{IL} / \mathrm{GC}
$$

where $\mathrm{GC}=$ ground covered by potato foliage (proportion) estimated with equation $5(21,25)$ :

$$
\mathrm{GC}=\operatorname{minimum}(1, \mathrm{LAI} / 3)
$$

The variables $t_{0}, t_{1}$, and $\mathrm{S}$ were obtained from the field experiments (average of replications), while LP, LAI, and LGR were generated by the model. Differences among experiments and cultivars for $\mathrm{IL}_{\mathrm{GC}}$ and DOI were investigated using analysis of variance in a completely randomized design. The Tukey's test ( $\alpha=0.05$ ) was used for comparing their means (23). Assumptions of normal distribution and homogeneous variance of experimental errors were tested as described by Neter et al. (27).

Comparison of RH measured above and within the canopy in order to estimate LWD. RH data from tropical highland sites measured within and above the potato canopy were used to esti-

\begin{tabular}{|c|c|c|c|c|c|}
\hline Location, department, year & Altitude $^{\mathrm{a}}$ & Latitude & Longitude & $\overline{\mathrm{T}}^{\mathrm{b}}$ & $\overline{\mathrm{H}}^{\mathrm{c}}$ \\
\hline Comas, Junín, 1999 & 2,400 & $11^{\circ} 34^{\prime} 42^{\prime \prime} \mathrm{S}$ & $75^{\circ} 5^{\prime} 35^{\prime \prime} \mathrm{W}$ & 13.8 & 19.5 \\
\hline Oxapampa, Pasco, 1999 & 1,800 & $10^{\circ} 33^{\prime} 55^{\prime \prime} \mathrm{S}$ & $75^{\circ} 23^{\prime} 55^{\prime \prime} \mathrm{W}$ & 17.4 & 15.4 \\
\hline Huancayo, Junín, 2000 & 3,300 & $12^{\circ} 1^{\prime} 45^{\prime \prime} \mathrm{S}$ & $75^{\circ} 14^{\prime} 0^{\prime \prime} \mathrm{W}$ & 12.0 & 10.6 \\
\hline Oxapampa, Pasco, 2000 & 1,813 & $10^{\circ} 35^{\prime} 31^{\prime \prime} \mathrm{S}$ & $75^{\circ} 23^{\prime} 0^{\prime \prime} \mathrm{W}$ & 16.5 & 16.6 \\
\hline
\end{tabular}
mate the RH threshold compensating for the location of the sensor above the canopy. Data from the following sites were used: Oxapampa (collected in 1999, $n=133$ days; and 2000, $n=21$ days);

TABLE 2. Information on the Peruvian locations where experiments to validate the LB2004 version of LATEBLIGHT were conducted

a Meters above sea level.

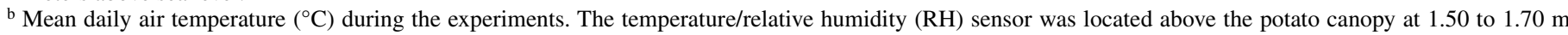
(Comas, Huancayo, and Oxapampa, 2000) or within the potato canopy at 0.15 to $0.50 \mathrm{~m}$ (Oxapampa, 1999).

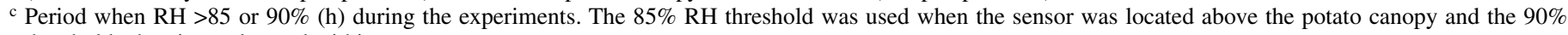
threshold when it was located within. 
Huancayo (collected in 2000, $n=31$ days) (Table 2); and Toluca (Mexico, 2,640 $\mathrm{m}$ above sea level, latitude $19^{\circ} 14^{\prime} 35^{\prime \prime} \mathrm{N}$, longitude $99^{\circ} 35^{\prime} 23^{\prime \prime} \mathrm{W}$; collected in $1998, n=76$ days; $1999, n=76$ days; and 2000, $n=87$ days) $(19,20)$, for a total of six data sets (location-year combinations). In Peru, RH was measured within and above a potato canopy as described previously, and both sensors were horizontally separated from each other by less than $1 \mathrm{~m}$. In Mexico, the data loggers used were Hobo (Model Pro RH/Temp) and Campbell (Model CR10X with 207-probe, Campbell Scientific, Logan, UT). The sensors were horizontally separated from each other by approximately $100 \mathrm{~m}$ and were sampled every 1 to 5 min.

For each data set, data from within the canopy were used to calculate the humid period (HP) as the number of hours when RH was above the original $90 \% \mathrm{RH}$ threshold. This was referred to as $\mathrm{HP}_{90}$ and was assumed to be the most accurate estimator of LWD, because the model was originally calibrated with LWD obtained with the $90 \%$ RH threshold (8). Data from above the canopy were used to calculate HP with six RH thresholds: 80, 82, 84, 86, 88, and $90 \%$. These values were divided by $\mathrm{HP}_{90}$ to obtain the efficacy (E, no units) of each RH threshold to compensate for the location of the sensor above the canopy. Values of $\mathrm{E}$ lower than 1 indicated that the new RH threshold was too high and, therefore, there was an underestimation of LWD, while values higher than 1 indicated the opposite.

Values of E (as predictor variable) and RH thresholds (as response variable) grouped by data sets were fitted to a random coefficient model using the Mixed procedure of SAS Software, release 9.1 (Statistical Analysis System, SAS Institute, Cary, NC) (24). Finally, a 95\% confidence interval for the RH threshold corresponding to $\mathrm{E}=1$ was calculated.

Simulations. The LB2004 version of LATEBLIGHT (4) was used to generate simulated epidemics. The program is available upon request from the corresponding author or from the Global Initiative on Late Blight website (GILB, available online from the International Potato Center [CIP]). A single simulation was performed for each epidemic (combination cultivar-location-year).

Environmental variables measured in each field experiment ( $T$, $\mathrm{H}$, and $\mathrm{TH}$ ) were used as driving variables of the model. Other input variables for which values were obtained from the field experiments were emergence date (estimated when $50 \%$ of plants emerged), date of the end of the epidemic (estimated as the length of the growing season of a healthy crop), and maturity level of the cultivar (early, mid, or late). Cultivars with fewer than 100 days from planting to maturity in a given location were considered as early-season, 100 to 120 days as mid-season, and more than 120 days as late-season $(31,38)$. Parameters for LGR, SR, and LP were those obtained in a previous study (4). Initial inoculum was calculated as described previously. In several replications of Comas and Oxapampa (2000), the first $S$ evaluation was done when the epidemic had already started and, therefore, $t_{0}$ was unknown. In those cases, $t_{0}$ was estimated as the day of emergence. In epidemics on cvs. Amarilis and Yungay in Huancayo, initial S was estimated at $1 \%$ and stayed at this level for several evaluations. In those cases, it was assumed that $\mathrm{S}=0 \%$ for all evaluations before the last evaluation with $\mathrm{S}=1 \%$ (described below).

At high levels of disease, the model sometimes showed erratic behavior with the proportion of infected tissue going up and down over time. This problem was corrected by reducing by $10 \%$ the effect of the proportion of infected tissue on lesion growth at $\mathrm{S}>$ $82 \%$.

Validation. Graphical comparisons were made by plotting observed and simulated disease progress curves (blight severity on time). This technique was used to subjectively evaluate for goodness of fit (35) and whether LB2004 possesses sufficient accuracy for its intended purpose, i.e., to predict the effects of environmental conditions and host resistance on late blight epidemics.
Statistical comparisons were made using AUDPC. This variable was used (and not RAUDPC as in the analysis of field data) because the observed and simulated epidemics had the same duration. Two statistical tests were applied. First, a slightly modified version of the confidence interval test (CIT) described by Alewell and Manderscheid (2) was used to compare mean $\mathrm{AUDPC}_{\mathrm{obs}}\left(\overline{\mathrm{AUDPC}}_{\mathrm{obs}}\right.$, percent-days) and mean simulated AUDPC $\overline{(\overline{A D P C}}_{\text {sim }}$, percent-days) according to equation 6 :

$$
\mathrm{CIT}=\frac{\sum_{i=1}^{n} \in\left[\left(p_{i} \geq L_{\mathrm{lower}, i}\right) \wedge\left(p_{i} \leq L_{\mathrm{upper}, i}\right)\right]}{n} \times 100
$$

where $p_{i}=\overline{\mathrm{AUDPC}}_{\mathrm{sim}}$ in the $i$ th epidemic, $\underline{L}_{\mathrm{lower}, i}$ and $L_{\mathrm{upper}, i}=$ lower and upper $95 \%$ confidence limits of $\overline{\mathrm{AUDPC}}_{\mathrm{obs}}$, respectively, in the $i$ th epidemic, and $n=$ number of epidemics. Values of CIT varied from 0 to $100 \%$ and represented the percentage of epidemics in which $\overline{\mathrm{AUDPC}}_{\text {sim }}$ fell within the 95\% confidence interval of $\overline{\mathrm{AUDPC}}_{\mathrm{obs}}$. In the original version of the test (2), CIT values represented the percentage that fell outside the confidence interval and the interval limits were not inclusive. Each comparison of $\overline{\mathrm{AUDPC}}_{\text {sim }}$ with the corresponding confidence interval of $\overline{\mathrm{AUDPC}}_{\mathrm{obs}}$ was equivalent to a hypothesis test to determine whether $\mu\left(\overline{\text { AUDPC }}_{\text {obs }}\right)$ is not different from a specified value $\mu_{0}$ ( $\overline{\mathrm{AUDPC}}_{\text {sim }}$ ) (37). Specifically, $\mathrm{H}_{\mathrm{o}}: \mu=\mu_{\mathrm{o}}$ and $\mathrm{H}_{\mathrm{a}}: \mu \neq \mu_{\mathrm{o}}$. The test statistic was $t$ and $\alpha_{\text {individual }}=0.05$. The assumptions of normality, absence of outliers, and independence of $\overline{\mathrm{AUDPC}}_{\mathrm{obs}}$ were previously verified in the analysis of the field data. The epidemics were grouped by location and cultivar, and CIT values were calculated for each of these groups. The performance criterion to consider the model valid was that $\overrightarrow{\mathrm{AUDPC}}_{\mathrm{sim}}$ had to fall within the $95 \%$ confidence interval of $\overline{\mathrm{AUDPC}}_{\mathrm{obs}}$ in at least $75 \%$ of the epidemics (34). The CIT did not provide information about the magnitude of the deviations, i.e., about the difference between $\overline{\mathrm{AUDPC}}_{\text {sim }}$ and $\overline{\mathrm{AUDPC}}_{\mathrm{obs}}$ (2).

The second statistical comparison was made using an equivalence test $(17,39)$ on AUDPC deviations. Equivalence tests are designed to test the null hypothesis of unequal means rather than that of equal means, as in the standard hypothesis framework (17). Thus, they are appropriate for model validation in which observed and simulated values are compared and the important finding is that both are equivalent (17). The following was done: (i) AUDPC deviations ( $\overline{\mathrm{AUDPC}}_{\text {sim }}-\overline{\mathrm{AUDPC}}_{\mathrm{obs}}$ ) were calculated and assumptions of normality, absence of outliers, and independence of observations were tested; (ii) a $95 \%$ confidence interval of the mean of AUDPC deviations based on a $t$ distribution was calculated (37); (iii) a tolerance range for AUDPC deviations, i.e., the interval within which the mean of deviations is considered acceptable, was defined; and (iv) the $95 \%$ confidence interval was compared with the tolerance range. The null hypothesis "the mean of AUDPC deviations is greater than the tolerance range" was rejected with a type I error of 5\% when the confidence interval of the mean of deviations fell within the tolerance range $(17,39)$. The performance criterion to consider the model valid was to reject this null hypothesis.

The tolerance range was determined based on the precision and accuracy of the measurement of blight severity, which is directly related to AUDPC. Using data reported by Forbes and Korva (Fig. $3 \mathrm{~A}$ in literature citation 12 [page 670]) and the method described by Hau (pages 126-127 in Campbell and Madden [9],), it was determined that evaluation of blight severity in the field using a percentage scale suffers by an inaccuracy of approximately $14 \%$ and an imprecision of approximately $12 \%$. It would be unreasonable to expect the model to perform as well as this, so a less strict tolerance range of $15 \%$ of the mean of $\overline{\mathrm{AUDPC}}_{\mathrm{obs}}$ was used.

Deviations of AUDPC were analyzed using the method described by Mitchell (26) and Willocquet et al. (39). This is a graphical method, although it was used in a quantitative manner. In contrast to the equivalence test, in which the mean of AUDPC 
deviations was compared with a predefined tolerance range, in this case each value of AUDPC deviation was compared with an envelope of acceptance. The envelope of acceptance was constructed by multiplying $\overline{\mathrm{AUDPC}}_{\text {sim }}$ by the tolerance range explained above (0.15). An indicator similar to CIT was calculated to obtain a quantitative measure, and we called it the envelope of acceptance test (EAT):

$$
\mathrm{EAT}=\frac{\sum_{i=1}^{n} \in\left[\left(d_{i} \geq L_{\text {lower }, i}\right) \wedge\left(d_{i} \leq L_{\text {upper }, i}\right)\right]}{n} \times 100
$$

where $d_{i}=$ AUDPC deviation obtained with LB2004 in the $i$ th epidemic, $L_{\mathrm{lower}, i}$ and $L_{\mathrm{upper}, i}=$ lower and upper limits of the tolerance range, respectively, in the $i$ th epidemic, and $n=$ number of epidemics. Values of EAT varied from 0 to $100 \%$ and represented the percentage of epidemics in which AUDPC deviations fell within the envelope of acceptance. The epidemics were grouped by location and cultivar, and EAT values were calculated for each of these groups. The performance criterion to consider the model valid was that AUDPC deviations had to fall within the envelope of acceptance in at least $75 \%$ of the epidemics.

\section{RESULTS}

Field experiments. The experiments were located in diverse environments: $\overline{\mathrm{T}}$ ranged from 12.0 to $17.4^{\circ} \mathrm{C}$ and $\overline{\mathrm{H}}$ from 10.6 to $19.5 \mathrm{~h}$ (Table 2).

Late blight epidemics started at different intervals after emergence (Fig. 1). In Comas, the disease was first observed 8 DAE; in Oxapampa 1999, 11 DAE; in Oxapampa 2000, 12 DAE; and in

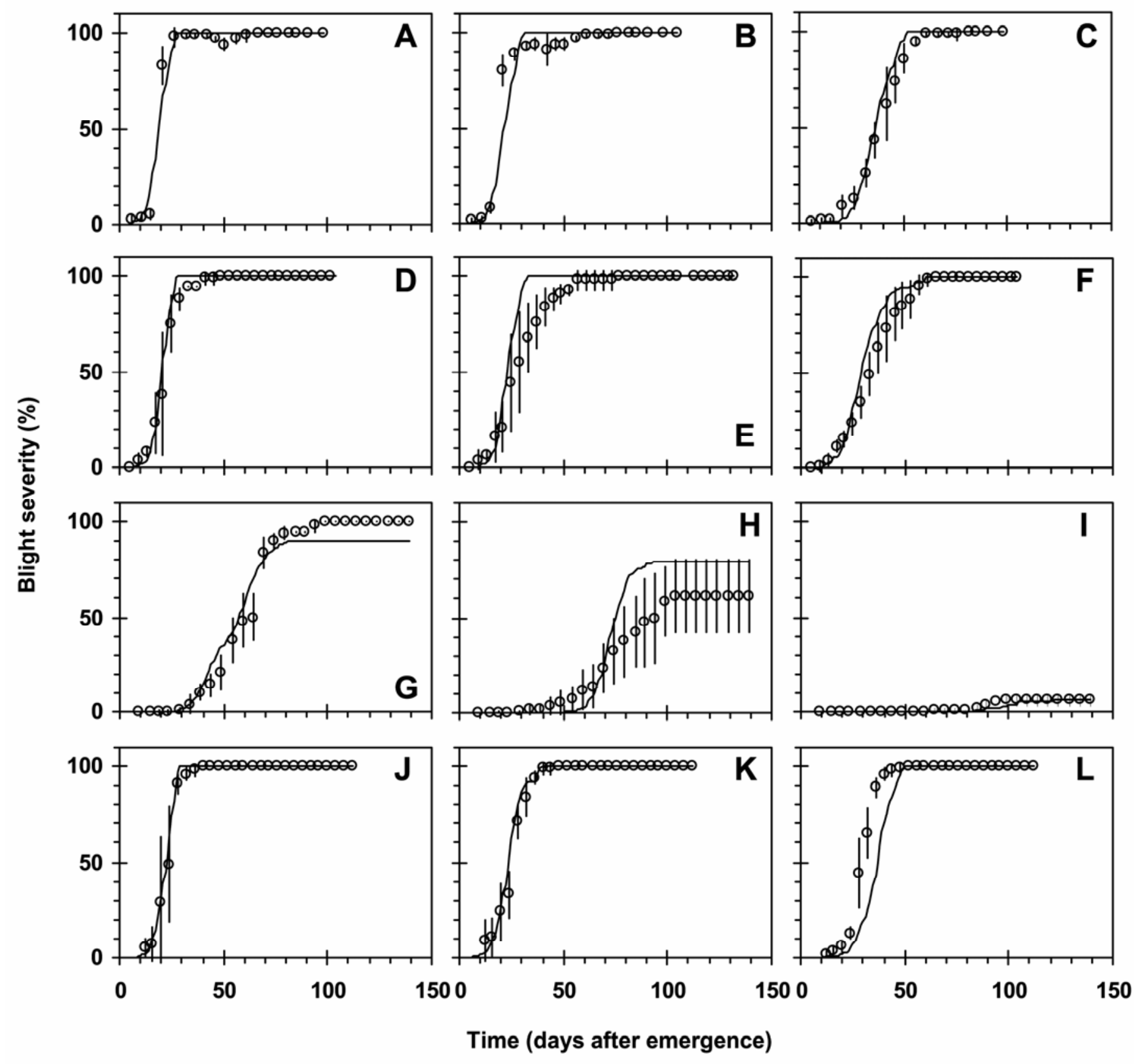

Fig. 1. Observed (circles) and simulated (continuous line) disease progress curves of epidemics of Phytophthora infestans in potato cultivars A, Tomasa, B, Yungay, and C, Amarilis in Comas, 1999; D, Tomasa, E, Yungay, and F, Amarilis in Oxapampa, 1999; G, Tomasa, H, Yungay, and I, Amarilis in Huancayo, 2000; and J, Tomasa, K, Yungay, and L, Amarilis in Oxapampa, 2000. The simulated progress curves were obtained with the LB2004 version of LATEBLIGHT. Vertical lines represent the standard deviation of the observed mean blight severity. 
Huancayo, 43 DAE (average values). The disease was detected earlier in susceptible cv. Tomasa and moderately resistant cv. Yungay (means of 15 and 16 DAE, respectively) than in resistant cv. Amarilis (26 DAE). Severity when the disease was first detected averaged $4 \%$ (standard deviation, $\mathrm{SD}=5$ ) and varied from 1 to $25 \%$, although in most cases it was between 1 and $5 \%$.

Late blight epidemics progressed very rapidly in Oxapampa and Comas, and slowly in Huancayo (Fig. 1). The mean period to reach 50\% severity was 25 DAE in Comas, 28 DAE in Oxapampa (1999), and 26 DAE in Oxapampa (2000), while in Huancayo it was 72 DAE, excluding cv. Amarilis which did not reach 50\% severity. Mean final severity was $100 \%$ in Comas and Oxapampa, and $72 \%$ in Huancayo. Cv. Tomasa ended the epidemics with mean severity of $100 \%$, cv. Yungay with $90 \%$, and cv. Amarilis with $77 \%$.

Analysis of field data. Analysis of $\overline{\text { RAUDPC }}_{\text {obs }}$ showed that the degree of within-treatment variability was relatively low (Fig. 2). The $95 \%$ confidence intervals of $\overline{\mathrm{RAUDPC}}_{\mathrm{obs}}$ were informative with one exception, cv. Yungay in Huancayo, for which the variability was high. Final severities in the four replications of this cultivar in Huancayo were 35, 60, 70, and $80 \%$.

$\mathrm{Cv}$. Amarilis was the most resistant, followed by cv. Yungay and cv. Tomasa according to the analysis of $\overline{\text { RAUDPC }}_{\text {obs }}$ (Fig. 2), although the degree of difference was related to disease severity in environment. In Huancayo, the three cultivars clearly separated from each other, while in Oxapampa the differences among them were nonsignificant $(\alpha=0.05)$. The location of Comas was intermediate, with cv. Amarilis being statistically more resistant than cvs. Yungay and Tomasa, and these two cultivars sharing the same rank.

Estimation of initial inoculum. Values of DOI varied significantly among experiments $(P=0.019)$ (Fig. 3). Mean DOI in Huancayo (46 DAE) was significantly later $(\alpha=0.05)$ than in Oxapampa, 1999 (7 DAE), Oxapampa, 2000 (5 DAE), and Comas (3 DAE). There were no statistically significant differences among

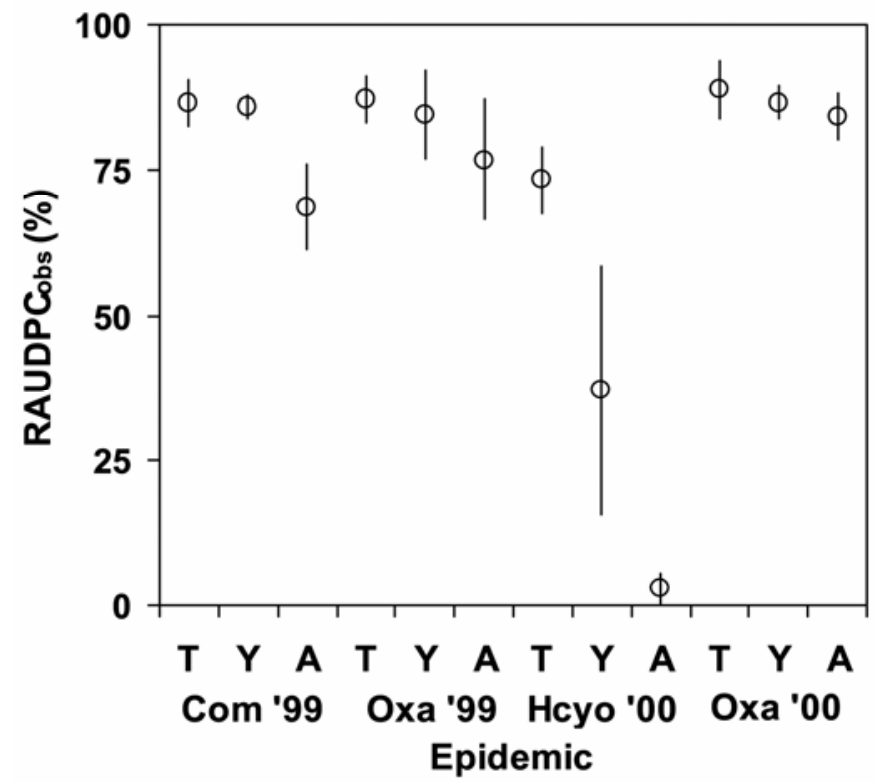

Fig. 2. Ninety-five percent confidence intervals of the mean of observed relative area under the disease progress curve $\left(\mathrm{RAUDPC}_{\mathrm{obs}}\right)$ in nine epidemics of Phytophthora infestans under field conditions in the Andes of Peru. An epidemic was defined as the combination of a potato cultivar $(\mathrm{T}=$ Tomasa, $\mathrm{Y}=$ Yungay, or A = Amarilis), a location (Com = Comas, Oxa = Oxapampa, or Hcyo $=$ Huancayo $)$, and a year $(99=1999$ or $00=2000)$. No fungicides were applied, and the epidemics started from natural inoculum. Within an experiment (combination location-year), cultivars with non-overlapping confidence intervals of $\overline{\mathrm{RAUDPC}}_{\mathrm{obs}}$ were statistically different among each other at $\alpha=0.05$. cultivars $(P=0.310)$, although the epidemics started later in $\mathrm{cv}$. Amarilis (24 DAE) than in cv. Yungay (12 DAE) and cv. Tomasa (9 DAE). Differences in $\mathrm{IL}_{\mathrm{GC}}$ were not statistically significant among experiments $(P=0.156)$ (Fig. 3$)$ or cultivars $(P=0.516)$. The average number of lesions per square meter of ground covered by potato foliage $\left(\mathrm{IL}_{\mathrm{GC}}\right)$ was 787 in Huancayo; 933 in Oxapampa, 2000; 1,445 in Oxapampa, 1999; and 2,338 in Comas, while the average number of lesions per square meter of ground (IL) was 491 in Huancayo; 17 in Oxapampa, 2000; 53 in Oxapampa, 1999; and 25 in Comas.

Comparison of RH measured above and within the canopy in order to estimate LWD. A random intercept model was used based on nonsignificant likelihood ratio tests for the variance of the slope and the covariance between the intercept and the slope $(P>0.050$ in both cases). The coefficients for the regression were $b_{0}=119.23$ (standard error, $\left.\mathrm{SE}=3.16\right)$ and $b_{1}=-34.61(\mathrm{SE}=$ $3.05)$, and both were different from zero $(P<0.001)$ (Fig. 4$)$. The variance of the intercept among locations was 4.76, and the residual variance was 2.58 . The $95 \%$ confidence interval of the $\mathrm{RH}$ threshold for $\mathrm{E}=1$ was 84.3 to $85.0 \%$. For convenience, $85 \%$ $\mathrm{RH}$ was used as the threshold to estimate LWD when the RH sensor was located above the potato canopy.

Validation. The LB2004 version met the predefined performance criteria in all the graphical and statistical tests. The disease progress curves generated by LB2004 were a reasonably accurate fit of those observed in the field (Fig. 1). The model was also able to predict the effect of environmental conditions (compare Fig. $1 \mathrm{C}$ and I) and host resistance (Fig. 1G and I) on late blight epidemics. In some cases, model predictions slightly underestimated (Fig. 1G and L) or overestimated (Fig. 1E) the disease, but these failures were judged to be minor.

The mean CIT value was $83 \%$, i.e., $\overline{\mathrm{AUDPC}}_{\text {sim }}$ fell within the $95 \%$ confidence interval of $\overline{\mathrm{AUDPC}}_{\mathrm{obs}}$ in 10 out of 12 epidemics (Table 3), and was higher than the predefined performance criterion that the model had to pass in order to be considered valid. In Comas and Huancayo, $\overline{\mathrm{AUDPC}}_{\text {sim }}$ fell within the $95 \%$ confidence interval of $\overline{\mathrm{AUDPC}}_{\mathrm{obs}}$ with all three cultivars, while it did not fall within the interval with cv. Yungay in Oxapampa, 1999, and with cv. Amarilis in Oxapampa, 2000.

In the equivalence test, the $95 \%$ confidence intervals of the mean of AUDPC deviations $(-142,468)$ fell within the predefined

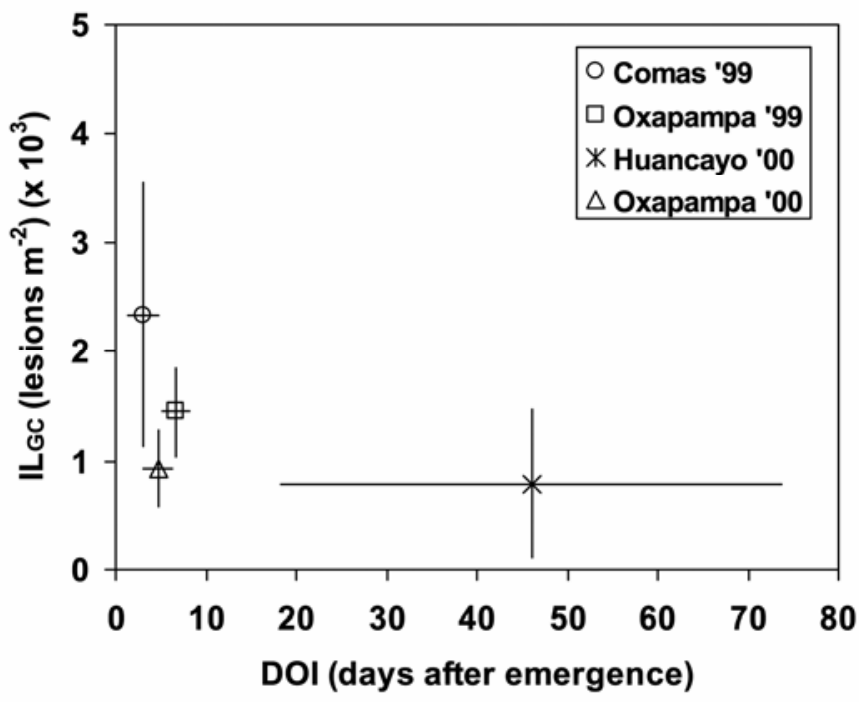

Fig. 3. Estimated initial lesions of Phytophthora infestans per square meter of ground covered by potato foliage $\left(\mathrm{IL}_{\mathrm{GC}}\right)$ and day of initiation (DOI) of the simulated epidemic in three locations of the Andes of Peru in 1999 and 2000. Each data point represents the mean of three cultivars, vertical lines represent the standard deviation of the mean of $\mathrm{IL}_{\mathrm{GC}}$, and horizontal lines represent the standard deviation of the mean of DOI. 
tolerance range $( \pm 1,071)$, i.e., the null hypothesis "the mean of AUDPC deviations is greater than the tolerance range" was rejected with $\alpha=0.05$ and, therefore, the differences between $\overline{\text { AUDPC }}_{\text {sim }}$ and $\overline{\text { AUDPC }}_{\text {obs }}$ were acceptable. The mean of AUDPC deviations fell within a tolerance range as low as $6.6 \%$ of the mean of $\overline{\mathrm{AUDPC}}_{\mathrm{obs}}( \pm 471)$.

Ten of twelve AUDPC deviations fell within the predefined envelope of acceptance, giving a mean EAT value of $83 \%$, which was higher than the predefined performance criterion (Table 3 ). In Comas and Oxapampa, the AUDPC deviations fell within the envelope of acceptance with all three cultivars, while in Huancayo, the deviations fell outside the envelope of acceptance with cvs. Amarilis and Yungay.

\section{DISCUSSION}

The LB2004 version of LATEBLIGHT accurately predicted the effect of weather and specific levels of host resistance on late blight epidemics occurring in the Andes of Peru. The approach of measuring LGR, SR, and LP of potato cultivars infected with isolates of a certain clonal lineage of $P$. infestans under controlled conditions (4) and then using the experimental results as parameters of LB2004 proved to be effective. The validated model can be used for educational and research purposes to illustrate concepts and to generate hypotheses about disease management using host resistance and manipulation of environment and initial inoculum. The domain of applicability of LB2004 is defined by (i) potato cultivars with similar resistance levels to $P$. infestans to those of cvs. Tomasa, Yungay, and Amarilis; (ii) P. infestans isolates with similar levels of aggressiveness to those prevailing in the field experiments; and (iii) environmental conditions within the range of those observed in Comas, Oxapampa, and Huancayo. We expect hypotheses tested with the model to have a good chance to be informative when these constraints are satisfied. Yet, we note that we cannot rigorously define the exact environmental boundary conditions, or the precise meaning of "similar" resis-

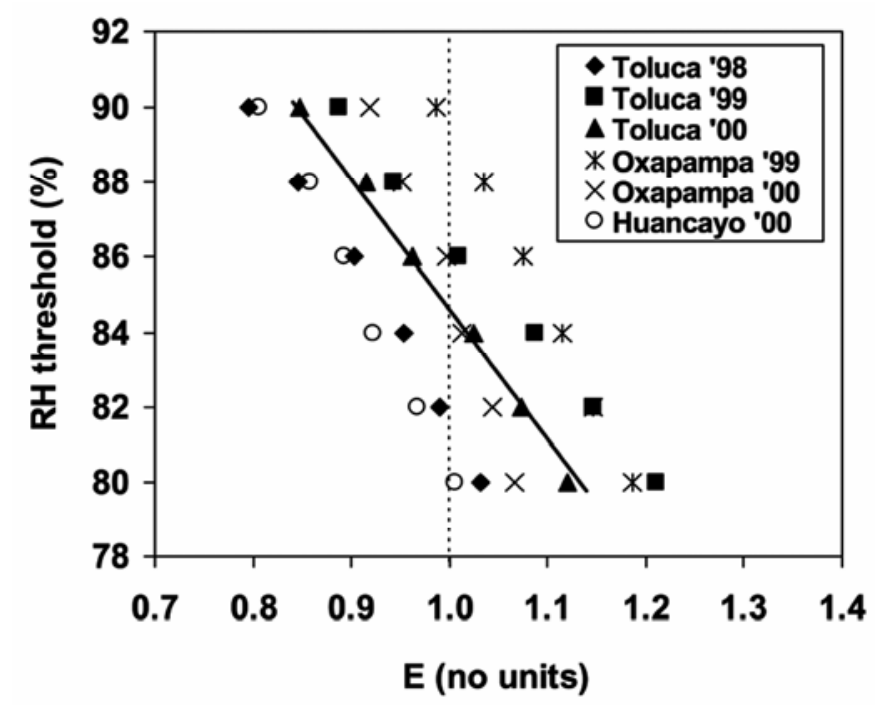

Fig. 4. Comparison of relative humidity $(\mathrm{RH})$ measured above and within the canopy in order to estimate leaf wetness duration (LWD). RH measured within a potato canopy from six location-year combinations was used to calculate the humid period (HP) as the number of hours when RH was above the commonly used $90 \% \mathrm{RH}$ threshold $\left(\mathrm{HP}_{90}\right)$. Data from above the canopy were used to calculate HP with $80,82,84,86,88$, and $90 \%$. These values were divided by $\mathrm{HP}_{90}$ to obtain the efficacy (E) of each threshold to compensate for the location of the sensor above the canopy. Values of E and $\mathrm{RH}$ thresholds grouped by data set were fitted to a random coefficient model, and the $95 \%$ confidence interval for the $\mathrm{RH}$ threshold corresponding to $\mathrm{E}=1$ was 84.3 to $85.0 \%$. We used $85 \% \mathrm{RH}$ as the new threshold to estimate LWD when RH was measured above the potato canopy. tance or aggressiveness levels. In all cases, any important conclusion from simulation analyses should be corroborated with field experiments.

Our approach to the operational validation of LB2004 had two key characteristics. First, we defined performance criteria to decide whether the level of agreement between model output and reality is acceptable. To our knowledge, there is no convention regarding the criteria that a plant disease model has to meet for being considered operationally valid. Thus, we followed suggestions by other authors and proposed a set of criteria. Second, the limits to decide whether the performance of the model is acceptable for each epidemic were defined based on variability of the field data. These two characteristics are crucial for the validation process because (i) operational validation can then be defined as a yes-or-no proposition (the model either does or does not meet the specified performance criteria); and (ii) data accuracy and precision define the limits for model testability, i.e., a model cannot be expected to generate results more accurate and precise than data of the real system (34). Our conclusion regarding the validity of LB2004 was based on the fact that the level of agreement between model output and reality was acceptable according to predefined subjective and objective performance criteria.

Field data analyzed as RAUPDC $\mathrm{obs}_{\text {s }}$ showed relatively low withintreatment variability (Fig. 2). This was unexpected since the epidemics started from natural inoculum, and under these conditions, epidemics tend to be more variable (20). This low variability could be explained in part by the way we calculated RAUDPC $\mathrm{Obs}_{\mathrm{os}}$. In those epidemics in which $\mathrm{S}$ reached $100 \%$ in a few days, RAUDPC $C_{\text {obs }}$ variability would be much higher if the epidemics had been truncated at the first evaluation with $S=100 \%$. However, such truncation does not allow for comparisons among epidemics in different locations/seasons (variation in length of crop growing period) or among different cultivars. In the case of cv. Yungay in Huancayo (Figs. $1 \mathrm{H}$ and 2), we decided not to consider any data point as an outlier, because we believe that this large variability was representative of the real system and not due to human error. We concluded that the field data were usable for validation of LB2004.

The performance of the model was sometimes erratic at high severity values. This problem was identified in the first version of LATEBLIGHT and apparently is due to an incomplete description of the relationship between disease density and epidemic develop-

TABLE 3. Values of the confidence interval test (CIT) and the envelope of acceptance test (EAT) obtained with the LB2004 version of LATEBLIGHT for epidemics grouped by location and year, and cultivar in Peru

\begin{tabular}{lccc}
\hline Group & $n^{\mathrm{a}}$ & $\mathrm{CIT}^{\mathrm{b}}(\%)$ & EAT $^{\mathrm{c}}(\%)$ \\
\hline Location, year & & & \\
Comas, 1999 & 3 & 100 & 100 \\
Oxapampa, 1999 & 3 & 67 & 100 \\
Huancayo, 2000 & 3 & 100 & 33 \\
Oxapampa, 2000 & 3 & 67 & 100 \\
Cultivar & & & \\
Tomasa & 4 & 700 & 75 \\
Yungay & 4 & 75 & 75 \\
Amarilis & 4 & 83 & 83 \\
Mean & 12 & & \\
\hline
\end{tabular}

a $n$, number of epidemics within each group.

b Values of CIT represent the percentage of epidemics in which the mean of the simulated area under the disease progress curve $\left(\overline{\mathrm{AUDPC}}_{\mathrm{sim}}\right)$ fell within the $95 \%$ confidence interval of the mean of the observed area under the disease progress curve ( $\left.\overline{\mathrm{AUDPC}}_{\mathrm{obs}}\right)$. The performance criterion to consider the model valid was that $\overline{\mathrm{AUDPC}}_{\text {sim }}$ had to fall within the $95 \%$ confidence interval of $\overline{\mathrm{AUDPC}}_{\mathrm{obs}}$ in at least $75 \%$ of the epidemics (34).

c Values of EAT represent the percentage of epidemics in which AUDPC deviations $\left(\overline{\mathrm{AUDPC}}_{\mathrm{sim}}-\overline{\mathrm{AUDPC}}_{\mathrm{obs}}\right)$ fell within an envelope of acceptance $\left(\overline{\mathrm{AUDPC}}_{\text {sim }} \times 0.15\right)$. The performance criterion to consider the model valid was that AUDPC deviations had to fall within the envelope of acceptance in at least $75 \%$ of the epidemics. 
ment (8). We removed this limitation by adjusting the density dependence for $\mathrm{S}>82 \%$. In practical terms, this adjustment is not relevant as opportunities for late blight management are essentially nonexistent at $\mathrm{S}>50 \%$.

The method we developed and used to estimate initial inoculum takes into consideration the size and resistance of the plant, the aggressiveness of the pathogen, and the environmental conditions. The variables DOI and IL are a function of LP and LGR, respectively, which in turn are defined by the cultivar-lineage interaction and temperature (4). The variable IL is also dependent on LAI, which in the current version of the model is a function of time (16). Thus, observed LAI could be lower than simulated LAI in plants growing in locations with low temperature and, therefore, IL could be overestimated. Replacing the current host submodel with a weather-driven potato simulation model would allow us to accurately estimate LAI and, therefore, IL and yield. First steps on that direction have been taken (32) using the LINTUL potato simulation modeling approach (22).

The method to estimate IL could be validated through fieldwork in which actual levels of inoculum are measured. Given a level of available inoculum, differences between cultivars in the number of lesions per square meter of foliage should be attributable to differences in infection efficiency, which is a fitness component that we have not measured.

We identified several considerations related to initial inoculum for future validation experiments: first, the intervals of the evaluations to detect the disease should be as short as possible (ideally daily) in order to accurately estimate $t_{0}, t_{1}$ and, therefore, DOI; and second, care should be taken to accurately estimate $\mathrm{S}$ because it is critical for estimation of IL. The importance of an accurate estimation of $\mathrm{S}$ is illustrated with epidemics on cvs. Yungay and Amarilis in Huancayo (Fig. 1H and I). In these epidemics, initial $\mathrm{S}$ was estimated at $1 \%$ and stayed at this level for several evaluations. However, when we estimated DOI and IL using the values of this first $\mathrm{S}$ evaluation, the model overestimated the disease (data not shown). In contrast, the performance of the model improved when the values for the last evaluation with $S=1$ were used. The most likely explanation for this behavior is that initial $\mathrm{S}$ was overestimated in the field and, therefore, IL for the simulated epidemic was also overestimated. Apparently, S values lower than $1 \%$ were scored as $1 \%$, or lesions caused by other diseases were scored as caused by $P$. infestans.

We noticed that LB2004 is very sensitive to the onset of the epidemic, which depends on the weather and the amount of inoculum that is available. This complicates its use because the availability of inoculum is not known for a given place and time. Field studies to determine inoculum loads and their effect on the onset of the epidemic would be useful, particularly if such work could lead to the development of a predictive model. Such a model will consider spore production, escape, transport, survival, deposition, and infection (5). First steps in that direction have been taken (6). At the end, this model will help to predict the risk of disease spread among fields.

There are some limitations in the method used to estimate LWD. The main assumption was that the period when $\mathrm{RH}$ exceeds $90 \%$, as measured within the potato canopy, was the most accurate estimator of LWD. This was assumed because LATEBLIGHT was originally calibrated with LWD obtained with this empirical model (8). However, it has been shown that the accuracy of the 90\% RH threshold can be unsatisfactory (18), and other methods to estimate LWD are available $(3,29)$. LATEBLIGHT might be improved by using a more accurate method to estimate LWD but, in such methods, in addition to air temperature and RH, more environmental variables such as wind speed and cloud cover are needed. These variables are often not available for many locations in developing countries such as those of the Andes.

The field experiments were located in areas with extreme or near-extreme environmental conditions for late blight (Table 2).
Comas and Oxapampa have environments highly conducive to the disease from December to March (the rainy season) and, because of that, are used by the breeding program of CIP to evaluate potato genotypes for resistance to $P$. infestans. Farmers do not grow potatoes in these locations during these months because late blight cannot be managed economically. In contrast, Huancayo is at or near the other end of the range of environmental conditions where late blight is not a major problem. We selected these locations in order to test the model under extreme or near-extreme conditions, but we lack information of the performance of the model under other extreme conditions and also under intermediate conditions. Testing the model in new environments as well as in other potato cultivars and $P$. infestans populations is covered in a future study.

\section{ACKNOWLEDGMENTS}

This study was supported by the International Potato Center (CIP) and US-AID Project "Computer Simulation Models: A Tool for Transferring IPM Technologies from Developed to Developing Countries" (C15-073TA-MOU-99). We thank N. Grünwald from USDA-ARS for providing weather data from Mexico and the following persons for their collaboration in the execution of the field experiments: W. Pérez, H. Goyas, J. Paredes, E. Porras, E. de la Torre, and F. Ventura from CIP; A. Párraga, C. González, and M. Rivera from the Universidad Nacional Daniel Alcides Carrión in Oxapampa, Peru; and Y. Amaro and J. Pérez from the Universidad Nacional del Centro in Huancayo, Peru.

\section{LITERATURE CITED}

1. Adler, N. E., Erselius, L. J., Chacón, M. G., Flier, W. G., Ordoñez, M. E., Kroon, L. P. N. M., and Forbes, G. A. 2004. Genetic diversity of Phytophthora infestans sensu lato in Ecuador provides new insight into the origin of this important plant pathogen. Phytopathology 94:154-162.

2. Alewell, C., and Manderscheid, B. 1998. Use of objective criteria for the assessment of biogeochemical ecosystem models. Ecol. Model. 107:213224.

3. Anderson, M. C., Bland, W. L., Norman, J. M., and Diak, G. D. 2001. Canopy wetness and humidity prediction using satellite and synopticscale meteorological observations. Plant Dis. 85:1018-1026.

4. Andrade-Piedra, J. L., Hijmans, R. J., Forbes, G. A., Fry, W. E., and Nelson, R. J. 2005. Simulation of potato late blight in the Andes. I: Modification and parameterization of the LATEBLIGHT model. Phytopathology 95:1191-1199.

5. Aylor, D. E. 1986. A framework for examining inter-regional aerial transport of fungal spores. Agric. For. Meteorol. 38:263-288.

6. Aylor, D. E., Fry, W. E., Mayton, H., and Andrade-Piedra, J. L. 2001. Quantifying the rate of release and escape of Phytophthora infestans sporangia from a potato canopy. Phytopathology 91:1189-1196.

7. Bruhn, J. A., Bruck, R. I., Fry, W. E., Arneson, P. A., and Keokosky, E. V. 1980. User's manual for LATEBLIGHT: A plant disease management game. Cornell Univ. Dept. Plant Pathol. Mimeo. 80-1.

8. Bruhn, J. A., and Fry, W. E. 1981. Analysis of potato late blight epidemiology by simulation modeling. Phytopathology 71:612-616.

9. Campbell, C. L., and Madden, L. V. 1990. Introduction to Plant Disease Epidemiology. John Wiley \& Sons, New York.

10. Crissman, C. C., Espinosa, P., Ducrot, C. E. H., Cole, D. C., and Carpio, F. 1998. The case study site: Physical, health, and potato farming systems in Carchi province. Pages 85-120 in: Economic, Environmental, and Health Tradeoffs in Agriculture: Pesticides and the Sustainability of Andean Potato Production. C. C. Crissman, J. M. Antle, and S. M. Capalbo, eds. Kluwer Academic Publishers and International Potato Center (CIP), Dordrecht, The Netherlands.

11. Doster, M. A., Milgroom, M. G., and Fry, W. E. 1990. Quantification of factors influencing potato late blight suppression and selection for metalaxyl resistance in Phytophthora infestans: A simulation approach. Phytopathology 80:1190-1198.

12. Forbes, G. A., and Korva, J. T. 1994. The effect of using a HorsfallBarratt scale on precision and accuracy of visual estimation of potato late blight severity in the field. Plant Pathol. 43:675-682.

13. Franco, E. (ed.) 1994. Catálogo de Semilla Básica de Papa en el Perú, Proyecto de Apoyo a la Producción de Semilla e Investigación para Mejorar la Productividad de Papa en el Perú (SEINPA), Lima, Perú.

14. Fry, W. E. 1977. Integrated control of potato late blight: Effects of polygenic resistance and techniques of timing fungicide applications. Phytopathology 67:415-420. 
15. Fry, W. E. 1978. Quantification of general resistance of potato cultivars and fungicide effects for integrated control of potato late blight. Phytopathology 68:1650-1655.

16. Fry, W. E., Milgroom, M. G., Doster, M. A., Bruhn, J. A., and Bruck, R. I. 1991. LATEBLIGHT: A plant disease management game-User's Manual. Version 3.1. Microsoft Windows adaptation by B. E. Ticknor and P. A. Arneson. Cornell Univ. Dept. Plant Pathol., Ithaca, NY.

17. Garrett, K. A. 1997. Use of statistical tests of equivalence (bioequivalence tests) in plant pathology. Phytopathology 87:372-374.

18. Gleason, M. L., Taylor, S. E., Loughin, T. M., and Koehler, K. J. 1994. Development and validation of an empirical model to estimate the duration of dew periods. Plant Dis. 78:1011-1016.

19. Grünwald, N. J., Romero Montes, G., Lozoya Saldaña, H., Rubio Covarrubias, O. A., and Fry, W. E. 2002. Potato late blight management in the Toluca valley: Field validation of SimCast modified for cultivars with high field resistance. Plant Dis. 86:1163-1168.

20. Grünwald, N. J., Rubio-Covarrubias, O. A., and Fry, W. E. 2000. Potato late-blight management in the Toluca Valley: Forecasts and resistant cultivars. Plant Dis. 84:410-416.

21. Haverkort, A. J., Uenk, D., Veroude, H., and van de Waart, M. 1991. Relationships between ground cover, intercepted solar radiation, leaf area index and infrared reflectance of potato crops. Potato Res. 34:113-121.

22. Kooman, P. L., and Haverkort, A. J. 1995. Modelling development and growth of the potato crop influenced by temperature and daylength: LINTUL-POTATO. Pages 41-59 in: Potato Ecology and Modelling of Crops under Conditions Limiting Growth. A. J. Haverkort, and D. K. L. MacKerron, eds. Kluwer Academic, Dordrecht, The Netherlands.

23. Kuehl, R. O. 2000. Design of Experiments: Statistical Principles of Research Design and Analysis. 2nd ed. Duxbury Press, Pacific Grove, CA

24. Littell, R. C., Milliken, G. A., Stroup, W. W., and Wolfinger, R. D. 1996. SAS System for Mixed Models. SAS Institute, Cary, NC.

25. MacKerron, D. K. L., and Waister, P. D. 1985. A simple model of potato growth and yield. I. Model development and sensitivity analysis. Agric. For. Meteorol. 34:241-252.

26. Mitchell, P. L. 1997. Misuse of regression for empirical validation of models. Agric. Syst. 54:313-326.

27. Neter, J., Kutner, M. H., Nachtsheim, C. J., and Wasserman, W. 1996. Applied Linear Statistical Models. 4th ed. WCB McGraw-Hill, Boston, MA.
28. Oyarzún, P. J., Taipe, J. A., and Forbes, G. A. 2001. Phytophthora infestans characteristics and activity in Ecuador-Country profile. Pages 1525 in: Proc. Int. Workshop "Complementing Resistance to Late Blight (Phytophthora infestans) in the Andes.” E. N. Fernández-Northcote, ed. International Potato Center (CIP), Lima, Peru.

29. Pedro, M. J., and Gillespie, T. J. 1982. Estimating dew duration. II Utilizing standard weather station data. Agric. Meteorol. 25:297-310.

30. Pérez, W. G., Gamboa, J. S., Falcón, Y. V., Coca, M., Raymundo, R. M., and Nelson, R. J. 2001. Genetic structure of Peruvian populations of Phytophthora infestans. Phytopathology 91:956-965.

31. Precheur, R. J. (ed.) 2003. Ohio Vegetable Production Guide. The Ohio State Univ. Bull. 672-03.

32. Raymundo, R. M., Andrade-Piedra, J. L., Juárez, H. S., Forbes, G. A., and Hijmans, R. J. 2002. Towards an integrated and universal cropdisease model for potato late blight. Pages 77-82 in: Proc. Global Initiative on Late Blight (GILB) Conference "Late Blight: Managing the Global Threat.” C. Lizárraga, ed. International Potato Center (CIP), Lima, Peru.

33. Refsgaard, J. C., and Henriksen, H. J. 2004. Modelling guidelinesTerminology and guiding principles. Adv. Water Res. 27:71-82.

34. Rykiel, E. J. 1996. Testing ecological models: The meaning of validation. Ecol. Model. 90:229-244.

35. Sargent, R. G. 1984. A tutorial on verification and validation of simulation models. Pages 114-121 in: Proc. 1984 Winter Simulation Conference. S. Sheppard, U. W. Pooch, and C. D. Pedgen, eds. IEEE Press, Piscataway, $\mathrm{NJ}$

36. Schlesinger, D., Crosbie, R. E., Gagné, R. E., Innis, G. S., Lalwani, C. S., Loch, J., Sylvester, R. J., Wright, R. D., Kheir, N., and Bartos, D. 1979. Terminology for model credibility. Simulation 32:103-104.

37. Snedecor, G. W., and Cochran, W. G. 1989. Statistical Methods. 8th ed. Iowa State University Press, Ames, IA.

38. Swiader, J. M., and Ware, G. W. 2002. Producing Vegetable Crops. 5th ed. Interstate Publishers, Danville, IL.

39. Willocquet, L., Savary, S., Fernandez, L., Elazegui, F. A., Castilla, N., Zhu, D., Tang, Q., Huang, S., Lin, X., Singh, H. M., and Srivastava, R. K. 2002. Structure and validation of RICEPEST, a production situationdriven, crop growth model simulating rice yield response to multiple pest injuries for tropical Asia. Ecol. Model. 153:247-268. 